\title{
Estudos Terminológicos e Aplicações da Filosofia da Linguagem
}

\section{Terminology Studies and Applications of Language Philosophy}

\author{
Márcia lvo Braz | UFPE | marciabraz.ufpe@gmail.com \\ Nelly Medeiros Carvalho | UFPE | nellycar@terra.com.br
}

Resumo: Partindo das percepções de Filosofia da Linguagem, com enfoque na Semiótica de Peirce e nas Investigações Filosóficas de Wittgenstein, o objetivo desse trabalho é relacionar teorias da Filosofia da Linguagem aplicáveis aos princípios da Terminologia Técnico-Científica. Para alcançar esse objetivo, foi realizada uma pesquisa bibliográfica na literatura de Filosofia, Linguagem e Terminologia tendo em vista a verificação das convergências entre aplicações comuns entre as três áreas. Esse estudo permitiu depreender que a Semiótica e a questão dos jogos de linguagem são requisito fundamental para que sejam compreendidos alguns dos princípios filosóficos da Terminologia TécnicoCientífica como, por exemplo, o ponto de partida que é a linguagem natural. Porém, ela se torna especializada de acordo com contexto de uso profissional, no qual a comunicação por termos científicos se dá mediante representações de signos que, mais uma vez, só adquirem sentido se forem partilhados pelos membros da comunidade, ou seja, se todos os envolvidos na comunicação comungam das mesmas regras desse jogo de linguagem. Essas constatações também se relacionam com o conceito contemporâneo de Swales acerca das comunidades discursivas.

Palavras-chave: Filosofia da Linguagem. Terminologia. Jogos de Linguagem. Semiótica.

Abstract: Based on the perceptions of Philosophy of Language, especially in Peirce's Semiotics and Wittgenstein's Philosophical Investigations, the objective is to relate theories of Philosophy of Language applicable to the principles of Technical-Scientific Terminology. In order to reach this objective, a bibliographic research was carried out in the literature of Philosophy, Language and Terminology in order to verify the convergences between common applications between the three areas. This study allowed us to understand that Semiotics and the question of language games are a fundamental requirement to understand some of the philosophical principles of Technical-Scientific Terminology, such as the starting point that is natural language. However, it becomes specialized according to the context of professional use, in which communication by scientific terms occurs through representations of signs that, once again, only acquire meaning if they are shared by the members of the community, that is, if all the Involved in communication share the same rules of this language game. These findings also relate to the contemporary concept of Swales about discursive communities.

Keywords: Philosophy of Language. Terminology. Language Games. Semiotics. 


\section{Introdução}

As ciências e as áreas de especialidade compõem universos que desenvolvem para si uma metalinguagem específica, bem como uma visão de mundo própria e consensual partilhada por seus membros. Aprender e apreender uma ciência implica na compreensão da sua linguagem ao conceder aplicação mais eficaz dos princípios, métodos e técnicas. Isso é possível através do entendimento epistemológico dos conceitos que permeiam a área do conhecimento e, dessa forma, remontam as questões da filosofia da ciência tal como as da filosofia da linguagem.

Desse modo, pode-se afirmar que, nos mais diversos campos disciplinares e áreas do conhecimento, é possível considerar a linguagem como o princípio necessário para as situações de comunicação e seus processos subjacentes, a exemplo do entendimento compartilhado acerca dos signos que representam os conceitos, do mesmo modo que ocorre com as regras que compõem os jogos de linguagem entre os membros de uma comunidade discursiva.

Esses pressupostos fundamentam os princípios da Terminologia TécnicoCientífica, que é apresentada numa tríade de possibilidades:

- como teoria, tratando da relação entre conceitos e termos especializados;

- como prática, abarcando um conjunto de métodos e atividades que se preocupam com a coleta, descrição, processamento e apresentação de termos;

- como produto, configurando-se em um conjunto de termos, ou ainda vocabulário de uma determinada área de especialidade técnico-científica.

A observação de princípios da Filosofia da Linguagem levanta alguns questionamentos: que conceitos da Filosofia são utilizados em estudos terminológicos? Quais as evidências dos princípios filosóficos que estão mais presentes na teoria e prática da Terminologia?

Partindo das percepções de Filosofia da Linguagem, com enfoque na Semiótica de Peirce e nas Investigações Filosóficas de Wittgenstein, o objetivo desse trabalho é relacionar teorias da Filosofia da Linguagem que se aplicam aos princípios da Terminologia Técnico-Científica. Para alcançar esse objetivo, foi 
realizada uma pesquisa bibliográfica na literatura de Filosofia, Linguagem e Terminologia, com o intuito de verificar convergências com aplicações comuns para as três áreas.

Desse modo, o trabalho está organizado da seguinte forma: inicialmente, é apresentada uma contextualização acerca da Filosofia da Linguagem com implicações da virada linguística; em seguida, desenvolve-se uma exposição sobre Terminologia e se demonstra como essa área se utiliza dos conceitos anteriormente discutidos; em um terceiro momento, são apresentadas as convergências identificadas nas áreas aqui referidas à conclusão.

\section{Filosofia da Linguagem: breve panorama e implicações da virada linguística}

As investigações que caracterizam a Filosofia da Linguagem partem desde as reflexões sobre a linguagem propriamente dita, enquanto capacidade humana de comunicação, até as investigações da filosofia que se utilizam da linguagem como instrumento. Significa que a Filosofia da Linguagem não trata apenas de investigações dos séculos mais próximos: desde os sofistas, que partiam da capacidade e da razão individual para a argumentação, e do Crátilo, de Platão, já surgem os questionamentos sobre as denominações e, ao longo dos séculos, diversas outras problemáticas e reflexões se estabelecem, incluindo sentidos hermenêuticos, através da busca da compreensão dos sentidos e da verdade, além de visões analíticas que dão privilégio aos aspectos cognitivo, formal, lógico etc.

$O$ interesse pela Filosofia da Linguagem inicia com a metafísica, com a tentativa de formulação dos fatos mais genericamente universais, incluindo a enumeração das categorias mais básicas, utilizados para falar sobre o mundo. Outro segmento que possibilita o estudo filosófico da linguagem é a Lógica, que trata das inferências e seus critérios de validade ou invalidade a partir da observação das premissas e conclusões. O estudo da Lógica revela que a validade ou invalidade depende das formas dos enunciados que compõem as premissas e as conclusões, traduzindo-se na linguística analítica. Fator que suscita o terceiro ponto que trata dos interesses da filosofia na linguagem, que é a epistemologia. 
Uma estrutura panorâmica da Filosofia da Linguagem abrange três posturas: analítica (a língua em si mesma, objetiva, clara);

- analítica-hermenêutica (logicidade, empirismo, sentido, uso do conhecimento, valores);

- pós-virada linguístico-pragmática.

Matos (201--?, p. 1), ao desenvolver um panorama com os pontos gerais da filosofia da linguagem ao longo dos séculos, destaca que:

Mesmo depois da desconstrução da metafísica, realizada por Kant, a
filosofia contemporânea, fiel ao propósito do "Logos" ocidental grego,
não deixou de perseguir seu objetivo de encontrar uma "filosofia
primeira", como a chamou Aristóteles. Mas essa "filosofia primeira", ao
longo dos séculos, mudou o seu foco. Na contemporaneidade não há mais
a investigação da "natureza" ou da "essência" das "coisas" ou dos "entes"
(ontologia,, nem tampouco a reflexão sobre as "noções" ou "conceitos"
da "consciência" ou da "razão" (epistemologia), mas sim a reflexão sobre
o "significado" ou o "sentido" de manifestações linguísticas (análise da
linguagem).

Nesse sentido, tem-se a análise da linguagem a partir das línguas naturais (ordinárias, ou cotidianas), ligadas ao mundo da vida, e as linguagens artificiais (formais, lógicas). Destaca-se também a visão de quem não tem como pensar em termos de uma linguagem formal se não considerar antes a linguagem ordinária, na qual o "debruçar-se sobre a linguagem ordinária" seria o próprio método filosófico.

Os filósofos do século $\mathrm{XX}$ descobriram a linguagem como mediadora do sentido e validade, em que a relação de significado entre sujeito e objeto se faz presente como parte constituinte da comunicação humana. Isso significa que deve existir entre os sujeitos da comunicação um entendimento recíproco sobre as palavras e o sentido empregado, sobre os quais a linguagem assume o papel de mediar e validar, realizada por meio de sinais linguísticos, conforme ensina Matos (201--?).

Essa constatação nos aproxima de Peirce, que trata justamente dos sinais como forma de mediar a relação com o objeto ou coisa representada que, ao ser resumido em sinal, pressupõe o pertencimento a um sistema linguístico partilhado pelos membros de uma dada comunidade, a fim de que haja o entendimento recíproco na comunicação. Isso revela a dimensão pragmática da linguagem, ou 
seja, o uso dos sinais linguísticos nas relações entre os indivíduos integra as dimensões semântica e sintática, além da compreensão intersubjetiva.

É importante mencionar que essa compreensão entre os sujeitos é a grande responsável pela comunicação e seus desdobramentos, a exemplo da validação das proposições e do caráter discursivo e argumentativo que resultam na reciprocidade dialógica. Esses pontos representam a pauta mais recente da Filosofia da Linguagem.

Embora esses aspectos da linguagem não representassem uma descoberta para a Filosofia, foram trazidos à discussão e reflexão apenas após a virada linguística, uma vez que, ao longo dos séculos, as pautas da Filosofia também estavam entrelaçadas com os momentos sociais e científicos que tiveram uma mudança significativa entre o final do século XIX e o início do século $X X$, quando as transformações sociais em decorrência da pós-Revolução Industrial, juntamente com a maior popularização das ciências, trouxeram novas perspectivas.

A teoria dos signos de Peirce inicia uma grande reflexão sobre as questões de denominação, de intersubjetividade e de comunicação, e seria largamente estudada posteriormente por diversos pensadores.

De acordo com Peirce, o signo provoca um processo de encadeamento, que convoca o objeto que representa e provoca um efeito ao receptor da mensagem. Além disso, é no receptor (ou intérprete) que reside o sentido do signo, pois dele dependerá a intepretação da representação que ao signo é atribuída, de acordo com sua percepção.

No que concerne à representação (ou semiose), temos três categorias: a qualidade, a relação diática e a relação triádica, nas quais:

Três modos distintos de ser apresentam-se à mente: a potencialidade, que Peirce denominará Primeiridade, presente naquilo que é livre, novo, espontâneo e casual; a existência ou fatualidade, denominada por Peirce Secundidade - como presença do outro -, da negação e da existência; e, por fim, a generalidade, denominada por Peirce Terceiridade, característica do contínuo, do pensamento e da lei. (SILVEIRA, 2007, p. 41).

Em outras palavras, temos a terceiridade como equivalente à dedução, a secundidade relacionada à indução e a primeiridade como “cognição de novas 
qualidades do ser-assim (também chamada retrodução ou hipótese)", conforme aponta Matos (20--?, p. 4).

Estes conceitos piercianos permitem o estabelecimento de uma relação com o pensamento de Wittgenstein, uma vez que este pressupõe que os sinais de uma língua sejam comuns a todos os indivíduos da comunidade. Essa pressuposição se assemelha às formas de vida wittgenstenianas que, imbuídas em uma comunidade, possibilitam a comunicação entre os indivíduose, além dos sinais linguísticos comuns a todos, compartilham as regras dos jogos de linguagem necessárias às diversas situações cotidianas.

A virada linguística, juntamente com suas implicações posteriores, está paralelamente correlacionada a questões linguísticas resultantes do caráter pragmático que dominou o estudo da linguagem na primeira metade do século $X X$, a exemplo dos estudos das linguagens científicas que tomaram força após os estudos dos signos e, ao passo que havia uma maior consolidação da comunicação científica, essa ciência ganhava mais proeminência, conforme será tratado a seguir.

\section{Terminologia: conceitos e relacionamentos com a Filosofia}

Diversas acepções filosóficas têm contribuído com a Terminologia ao longo do tempo, uma vez que a linguagem ocupa uma posição privilegiada na Filosofia, e seus desdobramentos implicam desde as primeiras reflexões até a virada linguística, que impactou diretamente no surgimento e consolidação da Terminologia como teoria e ciência. Isso ocorre como consequência do caráter essencialmente pragmático que os estudos terminológicos assumem e das características fortemente ligadas à filosofia analítica.

Para que as interseções entre esses dois polos sejam compreendidas, serão apresentados a seguir conceitos sobre a Terminologia, bem como suas características, com o intuito de embasar as discussões apresentadas na seção seguinte.

Ainda que considerada recente enquanto ciência e essencialmente arraigada à Linguística, a Terminologia remonta às mais primitivas formas de comunicação oral, 
diante da necessidade de nomear objetos e fenômenos, individualizando-os. Dahlberg (1978) comenta que o conhecimento se desenvolveu graças aos elementos da linguagem e, à medida que novos conhecimentos apareciam, também novos elementos linguísticos tornavam-se mais claros e distintos. A autora ainda destaca que esse processo é contínuo e inerente ao homem, uma vez que utiliza a linguagem como expressão de seus pensamentos.

Mais adiante, aparecem as marcas peculiares na linguagem de segmentos diferentes da sociedade, comuns a indivíduos que realizam atividades, e ficaram mais evidentes a partir do momento em que as ciências começaram a ser delineadas e o conhecimento registrado. Assim sendo, teríamos a linguagem comum para a comunicação natural/cotidiana - durante muito tempo utilizada para a transmissão oral dos fatos - e, além desta, as linguagens formalizadas, graças à organização social e consolidação da linguagem escrita e das ciências.

\begin{abstract}
A terminologia não é um fenômeno recente. Com efeito, tão longe quanto se remonte na história do homem, desde que se manifesta a linguagem, nos encontramos em presença de línguas de especialidade, é assim que se encontra a terminologia dos filósofos gregos, a língua de negócios dos comerciantes cretas, dos vocábulos especializados da arte militar, etc. (RONDEAU, 1984, p. 1)
\end{abstract}

Para o entendimento da Terminologia em relação aos preceitos filosóficos, parte-se de duas noções: a prática e a delimitação de uma área (SIQUEIRA, 2011). A primeira diz respeito à necessidade de nomeação de seres e coisas, o que se constitui em um dos fatores de favorecimento à comunicação oral humana para, desse modo, também colaborar com a solidificação das organizações sociais e para o surgimento da expressão escrita, que permitiu uma trajetória que mudaria a comunicação através da linguagem, até então condicionada às capacidades individuais. Em contrapartida, como segunda noção, tem-se o fenômeno das denominações científicas que, de acordo com Cabré (1993), ocorreu entre os séculos XVIII e XIX quando os cientistas, preocupados com a proliferação de denominações, sentiram necessidade de ordenar as relações entre formas $e$ conceitos, que acabavam dificultando a comunicação. 
As primeiras expressões de sistematização de um estatuto científico da Terminologia são, de certo modo, recentes e alguns estudos apontam Lineu (17071778) como um dos pioneiros do estudo terminológico, graças aos esforços voltados às taxionomias.

O desenvolvimento acelerado da ciência e da tecnologia que surgia nos séculos XIX e XX possibilitou a consolidação da Terminologia como ciência, cujos precursores são Lotte (1888-1950), da Escola Soviética de Terminologia, e Wüster (1897-1977), da Escola Austríaca. Rondeau (1984, p. 7) defende a "primazia soviética" e destaca que "é preciso dizer que foi na URSS que nasceu a Terminologia como disciplina científica, enquanto na Áustria se elaboravam métodos de tratamento dos dados terminológicos”.

Lotte iniciou suas investigações, se deteve aos aspectos teóricos e metodológicos e considerou a Terminologia como disciplina influenciada pela Filosofia. Porém, não teve visibilidade exponencial tal como Wüster, uma vez que a língua russa não seria tão difundida. Já Wüster, influenciado pela Lógica, se preocupou com o tratamento dos dados terminológicos e sua padronização. Este é um ponto no qual ele diverge de Lotte, que admitia a possibilidade de um mesmo termo tomar roupagens diferentes. Entretanto, o caráter mais normativo acabou se sobressaindo do mesmo jeito que as teorias de Wüster que, mesmo sendo reconhecido como base para as pesquisas desenvolvidas adiante, sofreu críticas justamente nessas mesmas bases.

“Na perspectiva contemporânea, o termo não deve ficar restrito ao âmbito normativo, mas ser analisado em seus diferentes contextos discursivos, o que permite encontrar seu valor como uma unidade significativa de uma área na perspectiva do uso" (SIQUEIRA, 2011, p. 18). Nesse sentido, ainda se destacam estudos mais recentes, com ênfase à Teoria Comunicativa da Terminologia, resultante dos trabalhos de Cabréno âmbito do IULA (Instituto de Linguística Aplicada de Barcelona), na Espanha; a Socioterminologia, com Gaudin (França) e Auger (Canadá); a Terminologia Cultural, com Diki-Kidiri (Senegal); a Terminologia Cognitiva, com Temmerman (Alemanha) e, ainda, diversos trabalhos que se 
utilizam da Teoria do Discurso e da Linguística Textual, mais voltadas aos aspectos linguísticos, semióticos e pragmáticos (LARA, 2004; SIQUEIRA, 2011).

É importante observar que dentro da mesma ciência terminológica podem-se distinguir três orientações diferentes, embora não excludentes entre si, conforme aponta Cabré (1993, p. 32):

- a primeira considera a Terminologia como disciplina autônoma e interdisciplinar, que serve às disciplinas técnico-científicas;

- a segunda está centrada na Filosofia, no que concerne à categorização lógica dos sistemas de conceitos e organização do conhecimento;

- a terceira diz respeito à Linguística, que considera a terminologia como subcomponente do léxico da língua e as linguagens de especialidade como subsistemas da linguagem geral.

As três orientações são frequentemente dissolvidas e acabam consideradas juntas em parte da literatura, uma vez que são interligadas pelo caráter essencialmente teórico-prático. Porém, para o presente ensaio, em especial será considerada a segunda orientação, da qual a categorização lógica de sistemas de conceitos se traduz nos aspectos práticos de ferramentas de mapeamento conceitual, como é o caso dos tesauros e ontologias, desenvolvidos para organização da informação e do conhecimento e, também, nos aportes teóricos para a construção dessas ferramentas constituindo - inclusive - uma sólida ligação com outras áreas, a exemplo da Organização do Conhecimento, cuja expressão inicialmente se deu pela Documentação, em que temas como a Teoria do Conceito são pilares centrais e denotam características pragmáticas e analíticas herdadas da Filosofia da Linguagem.

Nesse sentido, Cabré (1993) ainda salienta que a Terminologia compartilha com a Lógica o interesse fundamental pelos conceitos, pelos quais a segundas $e$ preocupa prioritariamente com a relação que se estabelece entre o objeto da realidade e aquilo que o representa, mediante um processo de abstração. Assim, a Terminologia toma da Lógica os princípios de relações e da sua simbologia para 
representar os conceitos e compartilha com a ontologia o interesse pela natureza dos seres da realidade e pelas relações que nela se estabelecem.

Os conceitos, que são objetos de estudo de áreas como a Filosofia, as Ciências Cognitivas, a Semiótica, a Terminologia, dentre outras, sofrem algumas variações de definição de acordo com as escolhas epistemológicas do campo do conhecimento. Porém, é possível reunir alguns consensos: Dahlberg (1992[2] apud ALVARENGA, 2001, p.8; FRANCELIN; KOBASHI, 2011, p. 206) apontou algumas dificuldades uma vez que, em suas origens gregas, três elementos compunham o conceito (horos): logos, pragma e noema. Na tradução para o latim, horos foi substituído por terminus, que equivaleria apenas ao logos grego, ou seja, ao caráter linguístico. Dessa maneira, muitos filósofos, ao longo da história, utilizaram terminus como conceito e também como elemento linguístico.

Entretanto, já no século XVIII, a tradução do horos foi retomada por Christian Von Wolff (1679-1754), considerando suas características de signo (termo) e conteúdo (ALVARENGA, 2001, p.8) e, logo, a etimologia da palavra se aproxima das definições atuais.

Felber (1984, apud MOTTA, 1987, p. 31) destaca que as reflexões pioneiras acerca dos conceitos são ainda mais antigas, podendo ser atribuídas às escolas filosóficas gregas, a exemplo das questões difundidas por Platão na sua obra Phaidron (teoria das ideias) que pode ser considerada como a primeira formalização sobre a temática conceitual. Contudo, junto ao Organon, de Aristóteles, vieram os fundamentos da Lógica que seriam, nesse caso, as leis básicas do conceito e reuniam características, raciocínio, inferência, definição etc. Esse conjunto denominou-se "Analityk".

Embora as reflexões mais densas só tenham despertado recentemente, se considerarmos o percurso histórico do tema, a partir da década de 30 as definições de conceito passaram a ser investigadas de maneira mais ampla, a princípio, por Horn e, mais tarde, por Dahlberg - cuja expressão está vinculada à Ciência da Informação que se ocupa, dentre outros aspectos, das representações conceituais para a representação do conhecimento e informação. 
Segundo Dahlberg (1976), que desenvolveu uma Teoria Analítica do Conceito, essa representação serve a qualquer trabalho que esteja relacionado com a padronização de termos, nos quais o pressuposto da teoria parte de que cada conceito possui um referente (objetos individuais ou em conjunto, fatos, atividades etc.) cujas afirmações podem ser verificadas. Em vista disso, essas afirmações poderiam ser resumidas em um termo que representará esse referente nos processos de comunicação, nos quais esses conceitos seriam individualizados pelos elementos que os constituem.

A questão conceitual é peça-chave para a organização conceitual de uma área do conhecimento e sua representação, objeto de estudo não apenas da Terminologia, mas que influencia na terminografia (prática terminológica) e na semântica, devido à busca, até certo ponto, pela individualização dos termos conceitualmente.

O interesse pela linguagem "controlada" que advém dos estudos em Terminologia, baseada nas questões filosófico-conceituais, tomam também um caráter pragmático em razão de sua função para a comunicação profissional.

\footnotetext{
Um termo não é apenas expressão de um nódulo conceitual das ciências ou designação de uma inovação tecnológica, mas é também forte recurso linguístico de precisão conceitual. $\mathrm{O}$ uso de termos contribui, em muito, para tornar a chamada comunicação especializada mais objetiva, menos sujeita a ambiguidades e, consequentemente, mais eficiente, porquanto favorece uma compreensão comum sobre os conceitos, objetos e processos expressos pelo componente terminológico (KRIEGER, 2006, p 1).
}

As linguagens de especialidade estão presentes no cotidiano da produção científica e de seu tratamento e, tal qual o estabelecimento de novas unidades terminológicas, desempenham um papel fundamental. Nesse sentido, a Terminologia tem sido 0 instrumento essencial para a representação de informações, especialmente científicas, e tem utilidade diretamente ligada à Organização do Conhecimento (enquanto dicionários léxicos e terminologias especializadas, a exemplo dos tesauros) no âmbito da Documentação, para que os registros do conhecimento sejam organizados, nos mais variados formatos (bibliotecas, bases de dados, repositórios científicos etc.), e possam ser acessados 
posteriormente, além de contribuírem tanto com o mapeamento e organização conceitual das áreas do conhecimento quanto com a manutenção das ciências e proporcionarem um entendimento entre os membros mais experientes e iniciantes.

Assim sendo, podemos dizer que os campos científicos se valem do conhecimento da linguagem - para que seja organizado o seu sistema conceitual -, e que os instrumentos documentais, frutos da Terminologia, são dispositivos comunicacionais para os membros das comunidades científicas que recorrem à reflexão acerca da linguagem e se fundamentam na teoria do conhecimento científico. Essa condição nos aproxima dos estudos realizados por Peirce em Semiótica, em que os signos fundamentais são a base para o domínio de conhecimento e são constituídos de elementos essenciais para a terminologia desse conhecimento.

O Pragmatismo de Peirce é um grande esforço intelectual de operacionalizar, entre outras coisas, a terminologia da ciência, responsável por representar a comunicação entre os conhecimentos dos cientistas. Peirce acreditava que com uma boa terminologia haveria segurança na produção de novos conhecimentos, tratando, assim, de associar a referida discussão ao método pragmatista e à Semiótica (ALMEIDA, 2011, p. 113).

A International Organization for Standardization (ISO) define Terminologia como uma atividade relacionada com a sistematização e representação de conceitos, ou ainda como um conjunto de termos (conceitos) que constituem uma determinada área. Nesse sentido, Vogel (2007, p. 73) destaca que:

A terminologia preocupa-se com conceitos, definições de denominações, com a compilação, decisão, apresentação, criação e normalização de termos de campos especializados para fins de comunicação entre especialistas e profissionais. É uma disciplina que permite identificar, de forma sistemática, o vocábulo de uma determinada especialidade $\mathrm{e}$ analisá-lo.

A descrição do léxico terminológico não visa o estudo da língua em si: ele é, por definição, especializado num domínio delimitado, cujos termos não podem ser polissêmicos tampouco remeter a vários domínios, ou seja, são noções compartilhadas no âmbito de uma determinada comunidade. Por exemplo, como popularmente nos referimos aos jargões e termos técnicos. 
A Terminologia realiza o controle da conceituação das palavras de um dado campo com o intuito de otimizar a comunicação/transferência de informações entre os membros de uma comunidade discursiva. Essa acepção é semelhante à de Lara (2004), que afirma que Terminologia pode ser considerada sob dois aspectos: terminologia teórica, que abarca metodologia, princípios que regem a compilação, a estruturação, o uso, a administração de conceitos; e terminologia metodológica, que seria um conjunto de termos relacionados a uma área de especialidade tendo, portanto, duplo aspecto - científico e lexicográfico.

As ciências e as áreas de especialidade compõem universos de discurso que compartilham entre seus membros perspectivas e vocabulário técnico, além de conceitos e métodos de comunicação, que são os instrumentos de poder entre os membros experientes e a condição necessária ao aprendizado dos que pretendem fazer parte da comunidade. Desse modo, a definição concisa de um universo conceitual e terminológico determina os fatos próprios de uma especialidade e, à medida que vai se constituindo, solidifica a ciência e a sua identidade epistemológica.

Logo, chega-se ao conhecimento de que as áreas de especialidade a que se referem as abordagens terminológicas são equivalentes ao que Swales (1990) denomina como comunidades discursivas. Essa constatação traz ao rol do presente ensaio acepções da Filosofia da Linguagem que convergem para essa perspectiva, a exemplo dos jogos de linguagem, desenvolvidos por Wittgenstein e da teoria dos signos de Peirce.

4 Os signos de Peirce, os jogos de linguagem de Wittgenstein e aproximação com a Terminologia

Embora a comunicação cotidiana seja realizada através da linguagem natural, ao considerar contextos específicos como atividades e estudos acadêmicos e grupos profissionais, adotam-se modos mais formais que são responsáveis, inclusive, pela individualização desses grupos e delimitação das questões epistemológicas que garantem, por exemplo, a não interferência das variações de significado, revelando 
um consenso e podendo, também, delimitar estratos ocupados pelos membros recém-ingressos e pelos proficientes.

Essas são características das comunidades discursivas apresentadas por Swales (1990) e denotam um princípio da Terminologia Técnico-Científica que não considera a significação de uma forma ampla, mas em comunidades e áreas bem delineadas onde, além de compartilharem de um rol conceitual e terminológico, os membros desenvolvem habilidades para o uso dessa linguagem técnica, ou seja, partilham de jogos de linguagem. É relevante mencionar, nesse sentido, que a premissa de compartilhamento de um mesmo campo linguístico é um atributo da teoria dos signos de Peirce para que exista o entendimento mútuo.

Além dos fundamentos filosóficos de Peirce que reverberam na Terminologia, destaca-se também a teoria da formação de hábitos, que é responsável pela elucidação do surgimento de um conceito, inicialmente em um estado de espontaneidade, “[...] até chegar à generalização e à origem dos símbolos ou das associações mentais convencionais, pois o processo de simbolização resulta em um conceito de um domínio de conhecimento” (ALMEIDA, 2011, p. 109).

Além do mais, as discussões acerca das linguagens são mais uma contribuição da Semiótica de Peirce para a Semiótica aplicada à Documentação e à Organização da Informação e do Conhecimento, porque são áreas que se utilizam dos princípios da Terminologia Técnico-Científica para desenvolverem seus estudos e ferramentas, como as linguagens documentárias, nas quais estão presentes uma gama de conceitos Peirceanos que constituem ocorrências comuns na área - como é o caso de semiose, signo, índice, classes de signos, dentre outros, conforme explica Almeida (2011).

As terminologias partem de definições e da organização conceitual de um domínio do conhecimento e, dessa forma, é clara a sua vinculação ao Pragmatismo e à Semiótica, além do fato de a temática terminologia ser evidente na teoria de Peirce porque, para ele, um dado conceito científico é um símbolo e através dos símbolos o pensamento científico se realiza. 
A adoção de uma terminologia científica também foi apontada por Peirce (2000). Entretanto, ele ponderava que a regulação dos termos não fosse rígida ou arbitrária em demasia, mas adequada ao uso comum dos participantes sem, porém, cumprir apenas meras convenções linguísticas e deixando margem às mudanças inerentes ao contexto de uso, visto que os próprios conceitos tendem à mudança conforme o avanço da ciência. Essa observação é pertinente a qualquer trabalho terminológico, onde a previsibilidade de inovação junto à necessidade de abrir a atualização constante dos instrumentos terminológicos, é um preceito que continua em plena coerência.

Além das contribuições de Peirce, que remontam à virada linguística e muito influenciaram as acepções da Terminologia, podemos associar outro filósofo que se enquadra nos princípios aqui relacionados: Wittgenstein.

Os jogos de linguagem, sob a perspectiva wittgensteiniana, buscam explicar o significado da palavra de acordo com o seu uso em um dado contexto (WITTGENSTEIN,2000), ou seja, existe a possibilidade de uma mesma palavra ou termo possuir variações que podem depender da construção frasal, da intencionalidade, ou da conotação e da interpretação de um dos sujeitos envolvidos na comunicação. O autor destaca que o significado não deve ser entendido como determinado ou como uma propriedade unívoca da palavra, mas as expressões linguísticas e a própria linguagem em contextos e objetivos específicos definem o seu propósito de uso.

Desse modo, uma mesma palavra pode abarcar significados diversos, de acordo com a intenção do falante, e são exatamente esses diferentes contextos de uso com seus objetivos específicos que Wittgenstein denomina “jogos de linguagem". Esse conceito pretende mostrar que as expressões linguísticas são sempre utilizadas de acordo com o contexto do falante. Logo, um signo não adquire significado pela associação a um objeto, mas pelo seu uso, determinado por regras.

Essa observação nos aproxima das características das comunidades discursivas assim como das propriedades da terminologia técnico-científica, dado que, da 
mesma forma que Wittgenstein critica a busca por uma generalização conceitual que dê conta de todos os significados que uma palavra possa compreender, o estudo do contexto específico que se faz presente nas ferramentas terminológicas segue o mesmo princípio.

Diferente dos dicionários comuns, que procuram reunir todos os possíveis usos de uma palavra ou expressão, os produtos terminológicos geralmente cobrem uma ciência específica ou área delimitada, na qual cada termo é referido a um único conceito e o tratamento das palavras polissêmicas é realizado através do uso de modificadores que indicam o sentido de cada termo. Por exemplo, em um tesauro onde a palavra "mercúrio" deve ser considerada como elemento da mitologia e como componente do sistema solar, o termo ocorre duas vezes na lista com a indicação do respectivo sentido, individualizando-os.

A impossibilidade de generalização e a ênfase no contexto de uso, presentes nos textos das Investigações Filosóficas de Wittigenstein, são pontos que levam alguns autores a classificarem a sua concepção como pragmática, fato que também é considerado nesse trabalho.

Outro ponto da obra que nos aproxima das comunidades discursivas é que, partindo do princípio de que os jogos de linguagem são realizados de acordo com as regras, elas podem ter um grau mais ou menos formal e o domínio dessas regras é um dos fatores determinantes para a pertinência e para o grau de proficiência de um membro da comunidade de discurso e, no caso da Terminologia, das comunidades acadêmicas. Além disso, conforme destaca Swales (1992), os próprios membros podem modificar o alcance das regras ou até mesmo substituí-las, fazendo com que haja nas linguagens técnicas uma atividade constante, com a qual a linguagem é uma forma de vida, ou seja, a junção entre cultura, visão de mundo e linguagem.

Portanto, diante dos pontos apresentados por Wittgenstein e Peirce identificam-se, em ambos, noções basilares da Filosofia para o desenvolvimento de estudos em Terminologia, que constituem núcleo básico para qualquer investigação no tema. 


\section{Conclusão}

De acordo com a discussão realizada no presente ensaio, constatou-se que as abordagens e as teorias da Filosofia da Linguagem compõem um rico e vasto universo de estudos que situam o surgimento e a evolução das investigações da linguagem. $O$ entendimento do surgimento e da evolução dessas investigações esteve sempre ligado às pautas da Filosofia ao longo do tempo, quando as indagações acerca do fenômeno linguístico são tão remotas quanto à própria consciência da comunicação.

Ao longo do texto, tratou-se das questões relacionadas à Filosofia da Linguagem e, inicialmente, foi realizado um breve percurso histórico. A situação da virada linguística foi problematizada como fator motivador para as reflexões mais aprofundadas nas linguagens de especialidade, através da Teoria dos Signos de Peirce e das Investigações Filosóficas de Wittgenstein, buscando convergências e tecendo, dessa maneira, as respectivas considerações.

Esse estudo permitiu depreender que a Semiótica e a questão dos jogos de linguagem são requisito fundamental para compreender alguns dos princípios filosóficos da Terminologia Técnico-Científica como, por exemplo, o ponto de partida que é a linguagem natural - mas que se torna especializada de acordo com contexto de uso profissional -, em que a comunicação por meio de termos científicos se dá pelas representações de signos que, mais uma vez, só adquirem sentido se forem partilhados pelos membros da comunidade, ou seja, se todos os envolvidos na comunicação comungarem das mesmas regras desse jogo de linguagem.

Essas constatações também se relacionam com o conceito contemporâneo de Swales acerca das comunidades discursivas, em que a capacidade de compreender as representações dos signos e de dominar as regras dos jogos de linguagem são pilares da sua teoria. Além do mais, temos margem para os estudos filosóficos da linguagem e sua relação com as linguagens de especialidade, nas quais se desenvolve a Terminologia enquanto mapeamento léxico e conceitual de uma área e como ciência propriamente dita. 
Nesse sentido, observou-se também que, embora os estudos em Filosofia da Linguagem estejam bem consolidados, os relacionamentos com a Terminologia carecem de investigações mais aprofundadas e isso pode se configurar ou se converter em objeto de pesquisas posteriores $e$, finalmente, em um aperfeiçoamento mais sólido desta ciência.

Notas

[1] Organização da informação, de acordo com Brascher e Café (2008), é o processo que envolve a descrição física e de conteúdo dos objetos informacionais, cujo produto do processo descritivo é a representação através de metadados. Já a Organização do Conhecimento diz respeito à descrição das características, conceitos, classificação e relacionamento com outros itens informacionais que abrangem o mesmo campo.

[2] DAHLBERG, Ingetraut. Knowledge organization and terminology; philosophical and linguistic bases. Internationalclassification, v.19, n.2, 1992, p.65.

\section{Referências}

ALMEIDA, C.C. Sobre o pensamento de Peirce e a organização da informação e do conhecimento. Liincem Revista, Rio de Janeiro, v.7, n.1, p. 104 - 120, março, 2011.

ALVARENGA, L. A teoria do conceito revisitada em conexão com ontologias e metadados no contexto das bibliotecas tradicionais e digitais. DataGramaZero: Revista de Ciência da Informação, v.2, n.6, Dez. 2001. Disponível em:

http://basessibi.c3sl.ufpr.br/brapci/index.php/article/view/0000001252/fd43bb9f0bbb0ba1 3eOae173e5695232 Acesso em 15 jan. 2017.

BRÄSCHER, M.; CAFÉ, L. Organização da Informação ou Organização do Conhecimento? In: ENCONTRO NACIONAL DE PESQUISA EM CIÊNCIA DA INFORMAÇÃO, 9, 2008, São Paulo, Anais. São Paulo: ANCIB, 2008. Disponível em:

<http://www.ancib.org.br/media/dissertacao/1835.pdf>. Acesso em: 30 out. 2011.

CABRÉ, M. T. La terminologia.teoría, metodología, aplicaciones. Barcelona: Ampúries, 1993.

DAHLBERG, I. Classification theory, yesterday and today. International Classification. v. 3, n. 2, 1976.

DAHLBERG, I. Teoria do conceito. Ci. Inf., Rio de Janeiro, v. 7, n. 2, 1978.

FRANCELIN, M.M.; KOBASHI, N.Y. Concepções sobre o conceito na organização da informação e do conhecimento. Ci. Inf., Brasília, v.40, n. 2, p.207-228, maio/ago., 2011. Disponível em: http://revista.ibict.br/ciinf/article/download/1311/1489 Acesso em $01 \mathrm{fev}$. 2017.

KRIEGER, M. G. Terminologia técnico-científica: políticas linguísticas e MERCOSUL. Ciência e Cultura, São Paulo, v.58, n.2, abr./jun., 2006. Disponível em: 
http://cienciaecultura.bvs.br/scielo.php?pid=s0009-

$67252006000200017 \&$ script=sci_arttext Acesso em 18 jan. 2017.

LARA, M. L. G. Linguagem documentária e terminologia. Transinformação, Campinas, v.16, n. 3, p. 231-240, set./dez. 2004

MATOS, I. Filosofia da linguagem. [s.I]: [s.n]. 20--? Disponível em: http://www.ismardiasdematos.com.br/filosofia\%20da\%20linguagem.pdf Acesso em 28 jan. 2017.

MOTTA, Dilza Fonseca da. Método relacional como nova abordagem para construção de tesauros. Rio de Janeiro: SENAI, 1987.

PEIRCE, C.S. Semiótica. 3. ed. São Paulo: Perspectiva, 2000.

RONDEAU, G. Introduction à laterminologie. 2. ed. Québec: GaëtanMorin, 1984.

SILVEIRA, L.F.B. Curso de semiótica geral. São Paulo: QuartierLatin, 2007.

SIQUEIRA, J. C. As noções de documento e informação: uma abordagem terminológica. 2011. Dissertação (Mestrado em Ciência da Informação) - Escola de Comunicação e Artes da USP, São Paulo, 2011.

SWALES, J. The Concept of Discourse Community. In: SWALES, J. Genre analysis: English in academic and research settings. Cambridge: Cambridge University Press, 1990. p. 21-32.

VOGEL, M. J. M. A noção de estrutura lingüística e de processo de estruturação e sua influência no conceito e na elaboração de linguagem documentária. 2007. Dissertação (Mestrado em Ciência da Informação) - Escola de Comunicação e Artes, Universidade de São Paulo, 2007.

WITTGENSTEIN, Ludwig. Investigações filosóficas. São Paulo: Nova Cultural, 2000. 